\title{
Sociedade em rede: perspectivas de poder no espaço virtual
}

\author{
Network society: perspectives \\ of power in the virtual space
}

Bruno FUSER ${ }^{1}$

RE S U M O

Neste artigo desenvolvemos reflexões sobre as conseqüências da intensificação do uso das tecnologias digitais nos diversos aspectos da sociabilidade, em especial na relação entre territorialidade e exercício da administração pública (governo eletrônico). Os novos espaços de sociabilidade, implementados no cotidiano particularmente com a difusão da Internet, remetem a diferentes dimensões da prática política, campo cada vez mais importante de estudo. As crescentes experiências de cidades digitais incorporam em medida diferenciada a interatividade das novas mídias como forma de participação dos cidadãos e desburocratização da política, configurando-se muitas vezes apenas como formas unidirecionais de transmissão de informações, desenvolvidas com o objetivo publicitário e/ou eleitoral.

Palavras-chave: sociedade em rede, globalização, desterritorialização, governo eletrônico, cidades digitais.

\section{A B S T R A C T}

In this article we develop considerations on the intense use of digital technologies and its consequences on several aspects of sociability, especially in the

\footnotetext{
${ }^{1}$ Doutor em Ciências da Comunicação pela ECA/USP. Professor titular de Jornalismo, Faculdade de Jornalismo. Líder do Grupo de Pesquisa Comunicação e Política. Professor convidado, Pós-Graduação em Ciência da Informação, Pontifícia Universidade Católica de Campinas. Praça Imaculada, 105, Vila Santa Odila, 13045-901, Campinas, SP, Brasil. E-mail: bfuser@puc-campinas.edu.br
} 
relationship between territoriality and exercise of the public administration (digital government). The new spaces for sociability, implemented in the daily life, particularly with the diffusion of the Internet, launched us to different dimensions of political practice, a field of study that is becoming increasingly important. Growing experiences of digital cities incorporate, in differentiated measure, the interactivity of the new media, as means for the citizens' participation and for the reduction of bureaucracy in politics, often constituting one-way forms of information broadcasting, developed for commercial advertising and/or electoral purposes.

Key words: network, globalization, de-territorialization, digital government, digital cities.

\section{N T R O D U Ç Ã O}

Os meios massivos de difusão de informação já exerceram, nas últimas décadas, papéis semelhantes aos de bandido e mocinho, por vezes simultaneamente. Foram descritos por imagens conflitantes ao extremo, como se constituíssem entes maléficos capazes de inocular comportamentos, sistemas onipresentes e onipotentes manipuladores de consciências e formadores de gostos homogêneos, instrumentos de potencialização de mercados novos e tradicionais, meios sensíveis à manifestação do receptor, formas de construção e manifestação de culturas. Por vezes de maneira entrelaçada, tais interpretações têm recebido novo e importante componente com os elementos que acompanham o discurso sobre as chamadas Tecnologias da Informação e da Comunicação (TICs).

Tais questões têm sido objeto de discussões e reflexões em diversos momentos. As conseqüências advindas da implantação da informatização de inúmeros setores da sociedade - como a eventualidade de estarmos vivendo em um mundo em que as relações são pautadas pela virtualização, um "real" latente, em oposição ao atual, e não ao concreto, como quer Pierre Lévy (1996) - encontram paralelo em outros períodos de inovação tecnológica. O automóvel e os trens já haviam, assim como a eletricidade e o telefone, imposto novos padrões de sociabilidade. Hoje, no entanto, ao debatermos a "sociedade em rede", a "era da informação" ou a "sociedade do conhecimento", somos intensamente tomados pela presença das redes de comunicação garantidas pela informatização da sociedade, em todas as esferas, desde o plano da política e do poder, até o das relações humanas mais sensíveis, como a afetividade.

Uma "segunda modernidade", a da era da cultura eletrônica, sincrônica e com multiperspectivas, baseada num sistema técnico (automóvel, avião, eletricidade, telecomunicações), verificou-se após uma "primeira modernidade", que se associa à Revolução Industrial, com as estradas de ferro, iluminação a gás, telégrafo, telefonia, conformando uma cultura tipográfica (diacrônica e linear), fundamentada na escrita (ORTIZ, 1991). Vivemos, agora, uma "terceira modernidade", com a disseminação das TICs. Estão em curso profundas mudanças de comportamento a partir do uso constante dos equipamentos de informática, associados à telecomunicação em grau de sofisticação até há pouco apenas imaginado, e em perspectiva de convergência tecnológica que apontaria para uma cibersociedade.

O momento de intensificação de tecnologias digitais traz conseqüências diversas no nível do cotidiano das pessoas, em todas as esferas, de maneira diferenciada, mas ampla. Na prática cotidiana da disseminação de informações isso é perceptível de 
múltiplas formas, a ponto de se tornar difícil a tarefa de se desenvolver qualquer atividade que não esteja total ou parcialmente inserida nos novos aparatos tecnológicos de informação. Os impactos das TIC's atingem o mundo do trabalho, as formas de coordenação inter e intra-empresariais e institucionais e os modos de consumo e de vida de milhões de pessoas por todo o globo, constituindo-se em fator de importância crucial para as grandes transformações por que o mundo vem passando nesta virada de século (BOLAÑO, 2003).

Essa "terceira modernidade", própria de uma Terceira Revolução Industrial - que tem como uma de suas características o "peso crescente do complexo eletrônico", como apontou Coutinho citado por Bolaño (1999, p.73) - é parte constitutiva de outro fenômeno, a globalização.

Assim como a globalização não é outra coisa senão o auge da internacionalização do capital monopolista, a indústria cultural é o ponto de partida para a constituição de uma cultura capitalista mundial que se expande (BOLAÑO, 1999, p.84).

\section{Internet e a nova cultura}

O elemento mais significativo na implementação dessa nova cultura é, sem dúvida, a Internet. Criada em 1969 com o objetivo de garantir a comunicação militar e científica estratégica nos Estados Unidos, em caso de guerra nuclear, a Internet desenvolveu-se de rede essencialmente científica, financiada por recursos públicos, para, hoje, uma crescente utilização comercial, em que o comércio eletrônico (e-commerce) e os negócios em rede (e-business) convivem com aplicações como correio eletrônico, grupos de discussão, educação à distância, bibliotecas virtuais, jornalismo online, telemedicina e teleconferências.

É a Interneta base da sociedade em rede, diz Castells:

Internet é sociedade, expressa os processos sociais (...) ela constitui a base material e tecnológica da sociedade em rede. (...) Esta sociedade em rede é a sociedade (...) cuja estrutura social foi construída em torno de redes de informação a partir de tecnologia de informação microeletrônica estruturada na Internet. Nesse sentido, a Internet não é simplesmente uma tecnologia; é o meio de comunicação que constitui a forma organizativa de nossas sociedades; é o equivalente ao que foi a fábrica ou a grande corporação na era industrial. A Internet é o coração de um novo paradigma sociotécnico, que constitui na realidade a base material das nossas vidas e de nossas formas de relação, de trabalho e de comunicação. O que a Internet faz é processar a virtualidade e transformá-la em nossa realidade, constituindo a sociedade em rede, que é a sociedade em que vivemos (CASTELLS, 2003, p.286-287).

André Parente (2000, p.171) reforça o conceito de rede:

A compreensão da época em que vivemos apóia-se, cada dia mais, sobre o conceito de rede. A rede atravessa hoje todos os campos do saber - da biologia às ciências sociais, passando pelas ciências exatas -, seja como conceito específico, em cada um destes campos, seja como paradigma e imagem do mundo, ou ainda como rede 
sociotécnica necessária à produção do conhecimento.

Esse pesquisador considera a rede "como que a condição de possibilidade do movimento de uma espécie de interconectividade generalizada". Essa interconectividade seria o fundamento de um novo tipo de pensamento, conexionista:

O conexionismo generalizado da sociedade das redes de computadores criou novas formas de espaço e tempo (...) Para pensarmos a nova ordem do capital - informação, a nova cultura do digital -, somos levados a pensar a partir de novos paradigmas comunicacionais (PARENTE, 2000, p.168).

André Parente sustenta que se criam a partir desses fenômenos novas perspectivas no campo da ciência, na medida em que se implantam interações entre o observador e o objeto do conhecimento.

As teorias científicas e artísticas contemporâneas não pensam mais a realidade em grupos de diferentes objetos, separados de nós, mas em grupos de diferentes interações que incluem o observador. Quando hoje se fala em interatividade (por ser sensório-motora) na multimídia, tratase do que chamamos de interatividade pobre, se comparada a esta que existe e que se estabelece como novo paradigma no campo do conhecimento. Como conhecer sem levar em conta a interação que se estabelece com o objeto do conhecimento? (PARENTE, 2000, p.173).

\section{Interatividade: perspectivas e limitações}

Essa interatividade sensório-motora a que refere Parente é uma das características da
Internet, assim como o conteúdo quase infinito a que se pode ter acesso. Se a interatividade já está presente em outros meios, como o rádio e, em menor escala, a televisão, o retorno e a possibilidade de participação do público alcançam (ao menos potencialmente) níveis muito diferenciados na nova mídia. De fato, jamais se chegou ao ponto de se instalar, em cada televisor, um aparelho para medir a audiência e, ao mesmo tempo, permitir ao espectador que se manifestasse livremente em relação ao que vê. Os aparelhos limitaram-se a amostragens sociológica e mercadologicamente convenientes, e a possibilidade de manifestação tem se restringido ou a pífios e predeterminados programas do tipo "você decide", ou, por outra via, através do pay-per-view, em que se escolhe entre algumas alternativas, permeadas sempre pela ótica do consumo.

A interatividade, vista como forma de participação direta num meio, extrapolou essas perspectivas televisivas, ou aquelas radiofônicas, de participação por telefone - "que música você escolhe". Interativa como telefone, a Internet disseminou o correio eletrônico - acrescendo-Ihe a possibilidade de salas de bate-papo, em que se garante a privacidade. Trouxe a possibilidade de recebimento, sem taxas adicionais, de mensagens de qualquer parte do mundo, e de qualquer tamanho ou formato, anexando-se arquivos.

É igualmente verdade, contudo, que a interatividade que se pode alcançar através da Internet dificilmente se realiza: trata-se essencialmente de escolher um produto para comprar, participar de uma enquete que busca traçar opiniões sobre assuntos da moda, entrar num bate-papo específico ou enviar e receber mensagens. A possibilidade de que os usuários interfiram decisivamente no conteúdo de um site dificilmente é aberta. Tivemos oportunidade de discutir tal questão em um estudo que buscou analisar o jornalismo online da região de Campinas. Ali destacamos que 
A propalada interatividade surge mais como ferramenta de segmentação, de detecção de tendências de consumo, do que propriamente como espaço à participação na produção de conteúdo (...). Assim, pode-se concluir que, embora haja possibilidades técnicas com a nova mídia de maneira inigualável para se estabelecer uma comunicação horizontal, interativa-que, através de outras estratégias, seria possível igualmente nas mídias como rádio, TV e impresso -, o que se vê nos casos estudados é a repetição de uma estrutura vertical, em que o usuário é levado a consumir informações, não a produzi-las, muito menos com a possibilidade de disponibilizá-las nos sites em questão. Portanto, confirmam-se afirmações como as de Samuelson (2000), segundo as quais há um enorme hiato entre os custos e as receitas dos negócios na Internet, o que permite vislumbrar uma concentração das empresas e a repetição de normas e regras que vigoram hoje na "velha economia" da comunicação (FUSER; SAMPAIO, 2001).

A repetição de aspectos da lógica da chamada "velha economia" no novo mundo globalizado é analisada por lanni (1995, p.112). Para ele, embora a globalização conduza à idéia de homogeneização da cultura, "é inegável que as mais diversas modalidades de organizar a vida e o trabalho, as heranças e as tradições, as façanhas e as derrotas, ou os trabalhos e os dias, continuarão a produzir e a desenvolver as diferenças, as diversidades e as polifonias". Ianni questiona os conceitos de identidade enquanto algo estanque, inamovível e salienta: "A identidade é ao menos em parte uma ficção ideológica. Por isso eu gosto da hipótese da transculturação, uma identidade múltipla, reconhecermos que somos polifônicos" (IANNI, 1997). Polifônicos, contraditórios, dialéticos.

\section{Dilemas da globalização}

O desemprego estrutural, a terceiromundização do primeiro mundo são alguns dos exemplos de problemas que a globalização traz, na medida em que globaliza o mercado de trabalho e as forças econômicas e sociais.

Numa ótica histórica e política, dá para dizer que a questão social é global, hoje, e que as lutas sociais se desenvolvem no Oriente Médio, na África do Sul, como em Londres, Paris, Nova lorque, e isso tudo está fertilizando o cenário mundial como um vasto palco da história, tanto de criações culturais, artísticas, econômicas, como de lutas sociais. Acho que não é exagero dizer que estamos entrando num novo ciclo de lutas sociais (IANNI, 1997).

Esse novo ciclo de lutas sociais têm um novo espaço, que é o espaço da sociedade mundo globalizada.

Renato Ortiz reflete sobre esse novo espaço. Após ressaltar que a desterritorialização é um dos traços essenciais da "modernidade mundo", Ortiz, citado por Bolaño (1999) aponta para a perspectiva da existência da cidade global, "um núcleo articulador do capitalismo mundial".

Diante da globalização do mercado, da fragmentação da produção, da deslocalização do trabalho, da flexibilidade das tecnologias, as instituições econômicas se rearticulam, determinando 'centros' de comando de suas atividades planetárias (Ortiz, citado por BOLAÑO, 1999, p.56). 
Ortiz assinala que o conceito de cidade global refere-se essencialmente à dimensão econômica, "uma cidade só é global quando se encontra dinamicamente articulada ao sistema capitalista mundial".

Poderíamos imaginar uma série de centros urbanos que, de alguma maneira, preenchem essa condição. São Paulo, Osaka, Cidade do México, Seul e Buenos Aires, em nível regional, concentram, relativamente, as funções que definem a globalidade (Ortiz, citado por BOLAÑO, 1999, p.57).

Para esse antropólogo, seria necessário distinguir a globalização das sociedades - em que assume particular papel a dimensão econômica - da mundialização da cultura, em que a questão do espaço se colocaria como "um conjunto de planos atravessados por processos sociais diferenciados":

A civilização da modernidade-mundo se caracteriza pois, como sendo, simultaneamente, uma tendência da conjunção e da disjunção de espaços. É isso que nos faz percebê-la como sendo marcada por duas direções, uma voltada para a homogeneização, outra, para a diversidade (...). Não existe uma oposição imanente entre 'local'/ 'nacional'/'global' (...). Uma primeira implicação da noção de transversalidade resulta na constituição de 'territorialidades' desvinculadas do meio físico" (...). Ocorre, na verdade, a constituição de uma territorialidade dilatada, compostas por faixas independentes, mas que juntam, superpõem-se, na medida em que participam da mesma natureza. Viajar, deslocar-se por esses estratos é permanecer no interior de um tipo de espaciali- dade comum a povos diversos (ORTIZ, 2000, p.62-66).

\section{Novas territorialidades}

As territorialidades desvinculadas do meio físico são discutidas também na perspectiva das cidades digitais,

um sistema de pessoas e instituições conectadas por uma infra-estrutura de comunicação digital (a Internet) que tem como referência comum uma cidade real (...) A sociedade da informação criou o espaço virtual, uma nova dimensão da cultura e da vida dos homens. Mas o espaço virtual existe como uma metacidade, isto é, como uma cidade universal em construção. O fundamento da existência das cidades é a relação e a proximidade humana (ZANCHETI, 2001, p.323).

$\mathrm{Na}$ administração das cidades digitais criam-se desafios: seus objetivos são os de

(...) criar um espaço de manifestação política e cultural das pessoas e grupos; criar um canal de comunicação entre pessoas e grupos; criar canais de comunicação e negociação entre a administração municipal e os cidadãos; favorecer uma maior identificação dos moradores e visitantes com a cidade referência; criar um acervo de informações das mais variadas espécies e de fácil aceso ( $\mathrm{sic}$ ) sobre a cidade referência (ZANCHETI, 2001, p.314).

Outra denominação que se tem dado a esse espaço de sociabilização é o de "cibercidades". Lemos assinala:

As ciber-cidades passam a ser pensadas como formas emer- 
gentes do urbano que, pelo potencial do ciberespaço, poderia restabelecer o espaço público, colocar em sinergia diversas inteligências coletivas, ou mesmo reforçar laços comunitários perdidos na passagem da comunidade à sociedade moderna (LEMOS, 2003).

Sílvio Zancheti assinala que as cidades digitais se desenvolvem sob duas perspectivas: as analógicas e as simbólicas. Enquanto aquelas estão voltadas para a referencialidade nas cidades reais, estas, as simbólicas, criam novos espaços, em que essa referencialidade não está presente.

Uma outra característica distintiva das CDs é a relação entre a cidade de referência (a real) e a cidade virtual $(\mathrm{a} C D)$. Existem pelo menos dois tipos de relação: uma analógica, outra simbólica.

Na relação analógica, a estrutura e a organização da CD correspondem aos atributos físicos do espaço urbano, especialmente 0 público, da cidade real.

Na relação simbólica não existe a correspondência entre elementos do espaço real da cidade e os componentes da CD. Nesse caso, em geral, é utilizada uma representação sem analogia com a cidade física, com conceitos completamente diferentes, tais como: grupo de discussão, anúncios, consulta a banco de informação, etc. (ZANCHETI, 2001, p.314).

André Lemos destaca que um dos objetivos das cibercidades é "lutar contra a exclusão social, regenerar o espaço público e promover a apropriação social das novas tecnologias" (LEMOS, 2003). Mas as limitações dessas iniciativas - consideradas no âmbito europeu projetos prioritários - são analisadas por Castells, para quem, nos usos pelas adminis- trações públicas, a Internet geralmente se restringe a um "quadro de avisos".

Em princípio, a Internet poderia ser um instrumento de participação cidadã extraordinário; de informação da classe política, dos governos e dos partidos aos cidadãos em seu conjunto, e de relação interativa. Poderia ser uma ágora política e sobre isso têm escrito todos os futuristas.

Atualmente, na prática, há experiências interessantes de democracia local, curiosamente local, como a Digital City, a cidade digital de Amsterdã (hoje passando por uma séria crise), as redes cidadãs de Seattle, o programa Iperbole em Bolonha (também em crise); mas, em geral, o que se observa é que os governos, as administrações, os partidos políticos confundiram a Internet com um quadro de anúncios. Em geral, limitam-se a expor dados: aqui está a nossa informação para que vocês fiquem sabendo o que fazemos, isso nos poupa trabalho e, se desejarem, podem nos dar a sua opinião. O que acontece é que não sabemos o que se passa com essa opinião (CASTELLS, 2003, p.279).

\section{Governo eletrônico}

O desafio de transformar o governo eletrônico, ou as cidades digitais, em espaços públicos de participação direta significa trazer a política para o campo da comunidade, uma comunidade que possa se expressar através da produção de informação eletrônica. Castells lembra, contudo, que

(...) todos os Parlamentos têm websites, todos os partidos têm Internet em todos os países desenvolvidos. No entanto, são vias, repito, unidirecionais de 
informação, para captar a opinião, simplesmente para converter os cidadãos em eleitores potenciais e para que os partidos obtenham informações para ajustar a sua publicidade.

Nesse sentido, o problema não é a Internet, e sim o sistema político. (...) lá onde existe burocratização política e política estritamente midiática de representação cidadã, a Internet é simplesmente um quadro de anúncios. É preciso mudar a política para mudar a Internet e, então, o uso político da Internet pode converter-se em uma mudança da política em si mesma (CASTELLS, 2003, p.280).

No campo da política, uma questão de pesquisa que se impõe é a de estudar de que maneira se dá a relação novas tecnologias de informação e política.

Em geral, temos escassíssimos exemplos de prática interativa cotidiana do sistema político com os cidadãos. Portanto, as fronteiras de pesquisa que gostaria de desenvolver sobre a Internet são as seguintes: de que maneira ela pode permitir a desburocratização da política e superar a crise de identidade dos governos que se verifica no mundo todo, a partir de uma maior participação permanente, interativa, dos cidadãos e de uma informação constante em mão dupla? Na realidade, isso não se produz (CASTELLS, 2003, p.279-280).

Implementar tais novas perspectivas de exercício de poder significaria superar barreiras de acesso, que não podem ser deixadas de lado. No entanto, embora existam tais barreiras acesso - no Brasil, têm acesso a computadores, cerca de $10 \%$ da população, enquanto teriam acesso à Internet aproximadamente $7 \%$ da população -, tem-se igualmente que superar as limitações de uso desses meios. A ponto de Castells afirmar que tal desafio é maior do que o próprio acesso.

O que se observa, contudo, naquelas pessoas, sobretudo estudantes, crianças, que estão conectadas é que aparece um segundo elemento de divisão social mais importante que a conectividade técnica: a capacidade educativa e cultural de utilizar a Internet. Uma vez que toda a informação está na rede - ou seja, o conhecimento codificado, mas não aquele de que se necessita -, trata-se antes de saber onde está a informação, como buscá-la, como transformá-la em conhecimento específico para fazer aquilo que se quer fazer. Essa capacidade de aprender a aprender; essa capacidade de saber o que fazer com o que se aprende; essa capacidade é socialmente desigual e está ligada à origem social, à origem familiar, ao nível cultural, ao nível de educação. É aí que está, empiricamente falando, a divisória digital neste momento. (CASTELLS, 2003, p.266-267).

Mesmo no que se refere à produção de conteúdo, é importante assinalar que a possibilidade de se publicar material na Internet, embora seja vasta, não foi suficiente para trazer de fato uma democratização nesse sentido ${ }^{2}$. A

\footnotetext{
2 Mas tais visões - que acentuam as diferenças, a busca de pluralidade, de expressão aberta e democrática na produção de informação e de cultura - não são, certamente, as únicas. Assertiva como a de Pierre Lévy é ilustrativa nesse sentido: "As mídias interativas e as comunidades virtuais desterritorializadas abrem uma nova esfera pública em que floresce a liberdade de expressão. (...) 0 desenvolvimento do ciberespaço já suscitou novas práticas políticas. São os primeiros passos da ciberdemocracia" (LÉVY, 2003, p.367).
} 
produção de informação permanece nesse meio, como nos demais, bastante concentrada.

Supunha-se que, em princípio, as tecnologias da informação e de telecomunicação permitiriam que qualquer um pudesse localizarse em qualquer lugar e prover, a partir dali, o mundo inteiro. O que se observa empiricamente é o contrário. Verifica-se uma concentração maior na indústria provedora de conteúdos de Internet, assim como de tecnologia de Internet, do que em qualquer outro tipo de indústria e concentra-se fundamentalmente nas grandes áreas metropolitanas dos principais países do mundo (CASTELLS, 2003, p.263).

\section{TICs e esfera pública}

A inserção das TICs na sociedade contemporânea seria, para alguns pesquisadores, a origem de uma reestruturação da esfera pública.

É essa revolução que está na raiz do desenvolvimento das novas TIC's, elemento central, por sua vez, na reestruturação da esfera pública, com o surgimento da televisão segmentada, da Internet e todas as inovações ligadas ao conjunto dos processos de comunicação, que modificam a estrutura das indústrias culturais, criando inclusive novas, e alteram as formas de interação e de reprodução simbólica do mundo da vida (...). Podemos falar em uma nova mudança estrutural da esfera pública, pois as novas TIC's põem em cheque o sistema global das Indústrias Culturais, vigente desde os anos 50 , ao atingir o seu núcleo central, a televisão de massa (BOLAÑO, 2003).
Também Zancheti (2001) reflete sobre a criação de um novo espaço público, virtual, a partir da implantação das novas TICs:

A sociedade da informação encontra nas cidades o seu necessário e principal campo de desenvolvimento, e será nelas que ocorrerão os experimentos para a construção do espaço virtual. A idéia de cidade digital é, portanto, uma conceituação preliminar para se descrever a construção do espaço público virtual nos seus primeiros estágios.

Consideramos que, embora as TICs introduzam novas formas de sociabilidade e tragam consigo potencialidades diversas, a forma como se dá o seu desenvolvimento não altera significativamente o papel que é exercido hoje pela indústria cultural. Contribui essencialmente para a manutenção dessa perspectiva a reprodução, no âmbito da produção de conteúdo, dos mesmos grupos pertencentes à indústria do entretenimento e da comunicação, assim como a manutenção de um padrão de televisão de massa, no Brasil, que supera amplamente a audiência da televisão segmentada. Vale dizer, que o consumo da TV por assinatura, majoritariamente, em grande medida reproduz padrões de programação (cinema, futebol) já presentes na TV de massa.

Assim, a sociedade em rede é uma realidade, mas as potencialidades de transformação que ela traz consigo, como destaca Castells, efetivamente não se realizaram. As diferenças, a polifonia a que lanni se referia anteriormente estão presentes. Movimentos como o do Fórum Social Mundial trazem à tona duas perspectivas bastante distintas de ação, mas que podem confluir para o questionamento de como se tem organizado a sociedade contemporânea.

Hardt (2003) considera que há duas tendências que buscam se contrapor à forma como se implementa a globalização: uma, 
antiglobalização, de cunho nacionalista, que opera através das organizações tradicionais, como partidos políticos, e outra, que opõe-se a qualquer solução nacional, defende uma globalização democrática, e que opera através dos movimentos em rede:

Os movimentos organizados em redes exercem seu poder mas não procedem por meio de oposições. Uma das características básicas da forma de rede é que dois nós não se enfrentam em contradição mas, pelo contrário, são sempre triangulados por um terceiro e depois um quarto e um número infinito de outros na rede. (...) Tomando um ponto de vista um pouquinho diferente, os movimentos meio que funcionam como uma esfera pública, no sentido de poderem permitir a expressão completa de diferenças dentro do contexto comum de trocas abertas. Mas isso não significa que as redes sejam passivas. As redes desalojam as contradições e realizam, em vez disso, um tipo de alquimia ou, melhor, uma mudança de maré que transforma as posições fixas tradicionais nos fluxos dos movimentos. As redes impõem sua força por meio de um tipo de corrente submarina irresistível (HARDT, 2003, p.346).

\section{Intelectual coletivo e hegemonia}

Em meio às disputas pela direção a ser tomada por movimentos contra globalização - ou contra a forma como se dá a globalização - destaca-se a importância dos meios de comunicação, considerados por Sodré (1996, p.73) uma espécie de 'intelectual coletivo' das novas tecnoburocracias gestionárias da vida social". Da mesma forma como ocorria, segundo
Gramsci, com a imprensa e os partidos políticos, os meios de comunicação de massa exerceriam hoje o papel de "dar coerência ou homogeneidade a um grupo social", ou seja, exercer a hegemonia, conforme destaca Sodré (1996, p.73).

Concorda com esse ponto de vista Caio Navarro de Toledo (1994), para quem a hegemonia - "a conquista do consenso sobre a sociedade civil" - se exerce de maneira central pelos media, "no terreno da cultura e da ideologia". Pontifica Toledo:

Tome-se o caso dos meios de comunicação de massa (mediante os quais se difundem e se produzem as informações, os valores, as opções políticas e eleitorais; onde se forjam novos comportamentos sociais e hábitos culturais, etc.). É, pois, de se perguntar: a mais extensa democratização dos meios de comunicação de massa (públicos e privados), na vigência da ordem capitalista, permitirá a veiculação, permanente e sistemática, de valores antiburgueses e de uma cultura política de orientação socialista e popular? O que dizer ainda da hipótese desses meios difundirem, no limite, interpelações massivamente anticapitalistas e revolucionárias? Nos regimes democráticos mais avançados nem de longe se pode vislumbrar essa possibilidade (TOLEDO, 1994, p.32).

Ainda que aponte de maneira otimista quanto às possibilidades de essa esfera pública vir a exercer um papel crítico, semelhante à esfera pública liberal-burguesa anterior ao desenvolvimento da indústria cultural, Bolaño (2003) assinala que essa perspectiva necessita de uma nova postura do trabalhador intelectual.

(...) o trabalhador intelectual, essa nova camada proletarizada, deve, 
superando os interesses mesquinhos e as hierarquias que a dividem, ajudar a organizar a luta contra a alienação e pela construção de uma sociedade mais justa, reconhecendo o seu papel histórico de mediador no processo de emancipação do Homem (BOLAÑO, 2003).

Tal ação defendida por Bolaño, em que deveriam se envolver os profissionais da Ciência da Informação interessados na construção dessa "sociedade mais justa", pode ser entendida como a construção do que Muniz Sodré (1996) define como "cultura democrática". Estimular uma "cultura democrática", no entender do pesquisador, implicaria cultivar a "expressão orgânica da pluralidade social, restituída a cada passo da cotidianeidade pela 'memória coletiva'”. Se a esquerda clássica não agiu dessa forma, tampouco os meios de comunicação de massa, que procurariam "legitimar o novo poder econômico-gerencial", significando "não memória, mas amnésia coletiva".

Continua Muniz Sodré:

$\mathrm{Na}$ realidade, o projeto de uma cultura democrática passa necessariamente pela dimensão da Ética (em seu estatuto distinto da moral, do direito e da estética), como experiência do reconheci- mento da diferença (ontológica) e, portanto, dos limites das determinações institucionais; Ética, entendida não como de ontologia privatista, mas como fundamento da liberdade humana, que possibilita a produção livre do sentido e a inserção dos sujeitos sociais em processos de verdade (SODRÉ, 1996) ${ }^{3}$.

\section{Perspectivas de estudos}

Consideramos que a sociedade em rede e as TICs trazem inúmeras perspectivas de estudo para a Ciência da Informação, seja em termos teóricos, seja para estudo de como se desenvolve o planejamento de ações de governo intermediadas ativamente por esse aparato sociotécnico, seja, ainda, na verificação das múltiplas formas de relacionamento existentes na sociedade em rede. Neste espaço buscamos trazer elementos para a reflexão sobre os novos espaços em que ocorre a sociabilidade, espaços nos quais co-existem diferenças e conflitos e também uma visão hegemônica, para cuja transformação torna-se necessária a participação do número cada vez crescente de profissionais de informação, que podem - devem? - atuar na construção de alternativas sociais no campo da cultura e da comunicação.

\section{RE FER Ê N C IA S}

BOLAÑO, C. Trabalho intelectual, comunicação e capitalismo: a re-configuração do fator subjetivo na atual reestruturação produtiva. Palestra proferida no programa de Mestrado em Ciência da
Informação da PUC-Campinas, Campinas, em 19/8/2003.

BOLAÑO, C. (Org.). Globalização e regionalização das comunicações. São Paulo: Educ, 1999.

\footnotetext{
3 As observações de Muniz Sodré sobre cultura democrática se aproximam bastante das preocupações relativas a uma política cultural que procuram resgatar o espaço da pluralidade e da cidadania. Bolognesi (1996, p.233), por exemplo, afirma, sobre a prática da administração petista em São Bernardo do Campo, entre 1989 e 1992: “Aquela política cultural, que procurou privilegiar a subjetividade, não poderia deixar de admitir o sujeito como cidadão. Daí, portanto, a premência em inseri-lo na organização e na administração dessa própria política. 0 caráter político, assim, complementou-se com a dimensão exata da participação nos processos decisórios, mais uma maneira de demonstrar que a ação cultural está para além do estritamente artístico".
} 
BOLOGNESI, M.F. Política cultural: uma experiência em questão: São Bernardo do Campo: 1989-1992. 1996. p.233. Tese (Doutorado em Comunicação) - Escola de Comunicação e Artes, Universidade de São Paulo, São Paulo, 1996.

CASTELLS, M. Internet e sociedade em rede. In: MORAES, D. (Org.). Por uma outra comunicação. Rio de Janeiro: Record, 2003. p.255-287.

FUSER, B.; SAMPAIO, C.V. Jornais online fecham-se à interatividade. In: COLLOQUIO ITALO-BRASILIANO DI SCIENZE DELLA COMUNICAZIONE, 2., 2001, Firenze. Resumo... Disponível em: <http://www.hypercampo.org/news/4 appuntamenti_colloquio.html>. Acesso em: $4 \mathrm{dez}$. 2003.

HARDT, M. Movimentos em rede, soberania nacional e globalização alternativa. In: MORAES, D. (Org.). Por uma outra comunicação. Rio de Janeiro: Record, 2003. p. 339-347.

IANNI, O. Teorias da globalização. Rio de Janeiro: Civilização Brasileira, 1995. p.112.

IANNI, O. Globalização. In: SEMINÁRIO INTERNACIONAL. A Arte na Era Contemporânea, 1997, Campinas. 1 cassete sonoro (60 min), mono.

LEMOS, A. Ciber-cidades. In: CENTRO Internacional de Estudos Avançados e Pesquisa em
Cibercultura. Ciberpesquisa. Disponível em: $<w w w . f a c o m$.ufba.br/ciberpesquisa/>. Acesso em: 29 ago. 2003.

LÉVY, P. O Que é Virtual. São Paulo: Ed. 34, 1996.

LÉVY, P. Pela Ciberdemocracia. In: MORAES, D. (Org.). Por uma outra comunicação. Rio de Janeiro: Record, 2003. p.367-384.

ORTIZ, R. Cultura e modernidade. São Paulo: Brasiliense, 1991. p.30-31.

ORTIZ, R. Um outro território. In: BOLAÑO, C. (Org.). Globalização e regionalização das comunicações. São Paulo: Educ, 1999. p.51-72.

PARENTE, A. Pensar em rede: do livro às redes de comunicação. Revista Brasileira de Ciências da Comunicação, São Paulo, v.23, n.1, p.167-174, 2000.

SODRÉ, M. Reinventando a Cultura. Petrópolis: Vozes, 1996. p.87-96.

TOLEDO, C. N. A modernidade democrática da esquerda: adeus à revolução? Crítica Marxista, São Paulo, v.1, n.1, p.27-38, 1994.

ZANCHETI, S.M. Cidades digitais e o desenvolvimento local. Recitec, Recife, v.5, n.2, p.311-329, 2001. Disponível em: <http://www.fundaj.gov.br/rtec/ art/fn1>. Acesso em: 4 dez. 2003. 